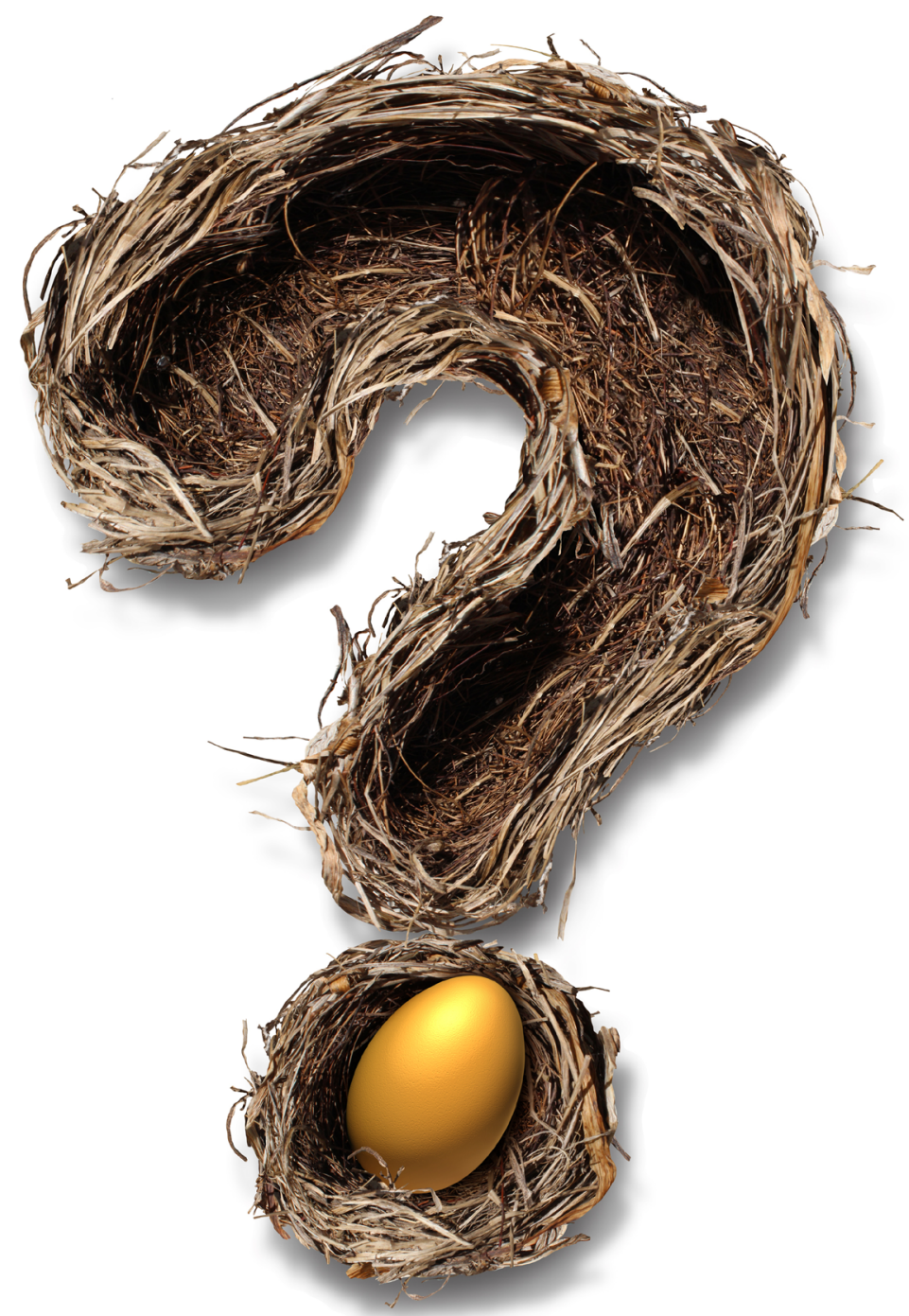

\title{
UM ABISMO ENTRE A TEORIA E A PRÁTICA DOS INVESTIMENTOS
}

OS MODELOS PARA CONSTRUÇÃO DE CARTEIRAS E GESTÃO DE RISCO DESENVOLVERAM-SE MUITO NAS ÚLTIMAS DÉCADAS, MAS OS GESTORES DE FUNDOS NÃO USAM PLENAMENTE ESSE FERRAMENTAL NO BRASIL. POR QUÊ? 


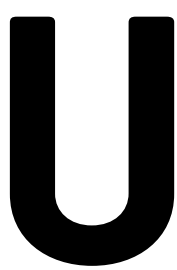

ma das decisões mais complexas no mundo dos investimentos é a construção da carteira. Quanto vamos alocar em cada tipo de ativo? Quais proporções devem ser mais eficazes? Qual é o risco da carteira resultante? Essas são questões que, há muitas décadas, têm permeado tanto o mundo acadêmico como o dos profissionais.

Desde os anos 1950, diversos modelos foram desenvolvidos para tentar resolver esses dilemas (veja no quadro da página seguinte). Contamos atualmente com uma teoria rica em técnicas para a construção de portfólios e gestão de risco. No entanto, como mostra recente pesquisa dos autores cujos resultados foram publicados na Revista de Administração, da Universidade de São Paulo (USP), no Brasil, o ferramental usado pelos gestores de fundos de investimento na construção das suas carteiras, bem como da gestão do risco, encontra-se distante das melhores práticas propostas pela academia.

Por exemplo, 91\% dos gestores que atuam no país usam como parâmetro de análise o retorno absoluto da carteira ou a rentabilidade adicional a determinado benchmark, porém essas medidas não consideram o risco dos investimentos. Existem, desde os anos 1960, métricas desenvolvidas pelos acadêmicos para cálculo de retornos ajustados aos riscos, que hoje são usadas por mais de $80 \%$ dos gestores de fundos na Europa. O que pode explicar esse abismo entre teoria e prática no Brasil?

\section{FATORES DE DISTÂNCIA ENTRE ACADEMIA E PRÁTICA}

Podemos citar diversos fatores. Na conclusão do artigo da Revista de Administração já apontamos alguns. Estudos acadêmicos no Brasil tendem a ignorar custos de transação, como corretagem e custódia, o que os torna pouco representativos da realidade. Também a baixa liquidez e a pequena quantidade de ativos disponíveis no mercado brasileiro não justificam os esforços necessários para a implementação de técnicas mais sofisticadas para a construção das carteiras e gestão do seu risco. Mas há mais, e podemos desenvolver uma série de argumentos que justifiquem o afastamento entre teoria e prática nas decisões de investimentos.

O primeiro tem relação com uma característica fundamental das carteiras de fundos de ações brasileiros: a imensa maioria deles tem carteiras muito similares ao seu benchmark principal, o Ibovespa, indicador do desempenho médio das cotações das ações negociadas na bolsa de valores brasileira. Quando estimamos os betas dessas carteiras - medida que relaciona a oscilação delas com um índice, nesse caso, o Ibovespa -, invariavelmente chegamos a resultados pouco

\section{BAIXA LIQUIDEZ DO MERCADO, DESCONHECIMENTO DE MÉTODOS QUANTITATIVOS E PREDOMINÂNCIA DE FUNDOS PASSIVOS SÃO FATORES QUE PODEM EXPLICAR POR QUE GESTORES DO BRASIL NÃO ADOTAM MODELOS DESENVOLVIDOS PELA ACADEMIA.}

abaixo de 1 . Ou seja, a volatilidade dessas carteiras é inferior ao benchmark. Betas abaixo de 1 indicam que o gestor adota uma postura defensiva e não gosta de ser surpreendido em movimentos bruscos do mercado, principalmente quedas. A emergência dos exchange traded funds (ETFs), que são produtos em geral indexados e de custos mais baixos do que os fundos de ações tradicionais, deve mudar essa característica. Afinal, não há sentido em gestores passivos cobrarem taxas de administração iguais à de produtos bastante ativos.

O segundo é que o uso de técnicas sofisticadas de construção de carteiras e gestão de risco exige um conhecimento de métodos quantitativos que muitas vezes está além da formação dos nossos gestores, e o uso adequado dessas técnicas exige formação muito sólida.

O terceiro é que os modelos são, em geral, baseados no passado e nas relações passadas entre as variáveis. Quando há mudanças nessas relações, que são chamadas em econometria de quebras estruturais, os modelos não funcionam. O exemplo mais famoso é o do fundo long-term capital management (LTCM), gerido por dois prêmios Nobel, Myron Scholes e Robert Merton, e que perdeu quase USD 5 bilhões após a crise asiática de 1997. O fundo usava um modelo baseado nas correlações entre diferentes variáveis econômicas que Scholes e Merton julgavam estáveis, mas não eram. As relações mudaram. O modelo desenvolvido pelos dois professores não acompanhou essas mudanças, e ainda não foi criado um modelo que efetivamente antecipe essas quebras estruturais. Numa economia instável como a brasileira, essa característica pode ser mortal para o sucesso do fundo de investimentos.

Talvez em função dessa última característica, os gestores de maior sucesso no Brasil, como Luis Stuhlberger, Paulo Bodin e Márcio Appel, aparentemente não usam modelos 


\section{A EVOLUÇÃO DA CIÊNCIA DOS INVESTIMENTOS Modelos para gestão de carteiras que surgiram desde os anos 1950}
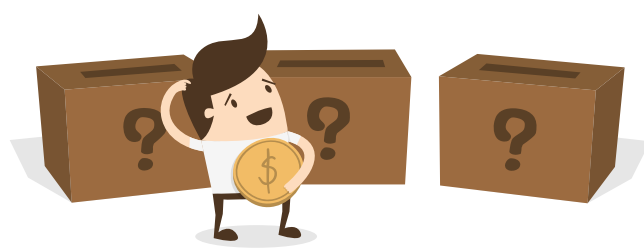

\section{MODELO MARKOWITZ}

Considerando a volatilidade como indicador de risco e as correlações entre os ativos, Harry Markowitz mostrou que é possível otimizar a relação entre retorno e risco construindo as chamadas carteiras ótimas. O problema, na época em que o modelo foi apresentado, em 1952, foi o volume de estimativas necessárias. Se estivéssemos analisando 50 ações, teríamos de estimar 2.450 correlações, um cálculo complexo para a época. Além disso, o modelo é baseado em estimativas, sempre difíceis de serem construídas e de se concretizarem.

\section{MODELO CAPM}

Em 1964, William Sharpe simplificou o problema colocado por Markowitz, criando o capital asset pricing model (CAPM), o qual contempla uma medida chamada beta, que relaciona o retorno de um título com um índice. Agora, para as mesmas 50 ações, só precisamos estimar 50 betas. 0 beta de uma carteira é a média ponderada dos betas dos ativos que a compõem. Ficou mais fácil construir carteiras, mas ainda é um modelo muito baseado em estimativas. Uma pequena mudança nelas muda muito a composição das carteiras propostas.

\section{MODELO GARCH}

Na década de 1980, Robert Engle e Tim Bollerslev observaram que a volatilidade de ativos é inconstante ao longo do tempo. Ao estudarem um fenômeno conhecido como agrupamento de volatilidade, eles propuseram o generalized autoregressive conditional heteroskedasticity model (GARCH). A ideia é que altas volatilidades são seguidas por altas volatilidades, e baixas volatilidades, por baixas volatilidades. Quando há uma mudança no nível da volatilidade, o modelo faz imediatamente o ajuste. Volatilidade e correlações de ativos estimadas nesse modelo costumam diferir significativamente da forma tradicional, baseada no desvio padrão de retornos, pois o GARCH é desenhado para corrigir rapidamente mudanças de padrões. O resultado são alocações e carteiras bem distintas.

\section{MODELO BLACK-LITTERMAN}

Em 1999, Fischer Black e Robert Litterman propuseram um modelo que tem como base a fusão da visão do investidor com a carteira de equilíbrio do mercado, isto é, a carteira de todos os ativos existentes. O Black-Litterman é um exemplo de modelo bayesiano, que permite adicionar convicções subjetivas individuais a modelos quantitativos financeiros. Mas, dada a sua complexidade, é pouco utilizado na prática.

\section{TRATAMENTO DE ERROS DE ESTIMAÇÃO}

Os modelos são baseados em algum tipo de previsão, o que pressupõe um volume grande de erros. Assim, surgiram alternativas para o tratamento de erros de estimação: a reamostragem, uma técnica que busca aumentar a base de dados para tomada de decisão; a carteira global de mínima variância, que impõe diversificação internacional e não considera retornos esperados na construção de carteiras; e o abandono dos modelos, com o uso, em seu lugar, de pesos iguais para todos os ativos ou de limites subjetivos de concentração máxima por ativo.

\section{TEORIA PÓS-MODERNA}

Concomitantemente à discussão de construção de carteiras, diversas alternativas à volatilidade foram propostas como medida de risco adequada para os investimentos, formando a base da chamada teoria pós-moderna de construção de carteiras. O uso da volatilidade como indicador de risco pressupõe que os retornos seguem uma distribuição de probabilidades simétrica. Esse pressuposto está bem distante da realidade, pois sabemos que há mais eventos extremos no comportamento dos ativos financeiros do que a distribuição normal. Isso significa que há mais momentos de perdas e ganhos do que o previsto com o uso da volatilidade.

Assim surgiram novas medidas de risco, como a semivariância, que mede a volatilidade dos prejuízos e ignora a volatilidade dos lucros. O próprio Markowitz acabou por admitir que considerava a semivariância uma medida superior de risco que a variância, por focar nas perdas.

Outras medidas consideram o risco de cauda de um ativo. O value at risk (VaR) dá-nos a perda máxima esperada para um portfólio dados determinado horizonte de tempo e determinado nível de confiança estatístico. Também temos o conditional value at risk (CVaR), que nos dá a perda esperada em um evento extremo e negativo, isto é, um momento muito ruim do mercado. O VaR fornece para o gestor de recursos uma ideia do prejuízo máximo em tempos normais, ou seja, levando em conta que crises que estouram uma vez a cada século não vão acontecer nos próximos meses. O CVaR dá uma ideia para o gestor do prejuízo esperado se essa crise rara e extrema ocorrer. Estimativas do VaR e CVaR permitem ao gestor fazer apostas responsáveis, de acordo com os limites que podem ser suportados.

quantitativos de construção de portfólios, mas, por meio de muito estudo, análise de relatórios e de outras informações, conseguem antecipar movimentos de mercado.

\section{PERSPECTIVAS}

Enfim, há uma distância grande entre o que é proposto pela academia e o que é praticado pelos gestores brasileiros. Isso se deve a inúmeros fatores que vão desde a instabilidade da economia brasileira até a baixa liquidez e a pequena quantidade de ativos disponíveis. Com o amadurecimento da economia e do mercado de capitais brasileiro, o domínio de técnicas quantitativas de construção de portfólio e de gestão de risco tende a se tornar um diferencial. Gestores devem se preparar para tanto, buscando aperfeiçoar sua formação nas técnicas mais modernas.

STEFAN COLZA LEE > Professor da FK Partners, doutorando em Finanças pela FGV EAESP e pesquisador do Centro de Estudos em Finanças da FGV EAESP (FGVcef) > stefan.lee@fkpartners.com

WILLIAM EID JUNIOR > Professor titular e coordenador do Centro de Estudos em Finanças da FGV EAESP (FGVcef) > william.eid@fgv.br 